\title{
A CONSTITUINTE, A JUSTIÇA E A MAGISTRATURA
}

\author{
José Eduardo Faria(1)
}

\begin{abstract}
RESUMO: Embora a reforma do Judiciário seja um dos temas mais importantes para a consolidação do processo democrático, a Assembléia Nacional Constituinte tem tratado essa questão de modo impreciso e incompleto. Por isso, desde ja se torna possivel imaginar o risco de colapso nas instituições judiciais brasileiras, na medida em que elas não estão preparadas para responder de maneira efetiva $e$ legitima aos conflitos e dilemas emergentes numa sociedade cada vez mais complexa e contraditória. Organizado em conformidade com o modelo liberal de organização do Direito e do Estado, o Judiciário neutro $e$ imparcial é a pedra-de-toque de uma cultura juridica altamente legalista em descompasso com uma realidade não-legalista. O artigo conclui propugnando pelo reconhecimento do papel político do Judiciário e pela expansáo de suas funções, a fim de que possa tentar compor interesses $e$ abrir caminho para um direito mais espontâneo $e$ em consonância com as aspirações dos diferentes setores sociais em conflito.
\end{abstract}

\begin{abstract}
Although the Judiciary reform is one of the most important themes for the consolidation of the democratic process, National Constituint Assembly has treated this question incompletely. Therefore, it has been possible to conceive the risk of total colapsus in the core of the Brazilian judicial institutions, since they haven't been well prepared for giving effective and legitimate answers to the dillemas and conflicts geared by an increasingly contradictory and complex society. Organized in accordance with the liberal model of State and Law, the presumptive neutral and fair Judiciary is the touch stone of a highly legalist juridical culture in complete contradiction with a non-legalist reality. This article concludes by claiming the recognition of the political role of the Judiciary and by poiting out the expansion of its social functions, thus trying to compose different social, political and economical wishes and to shape a more spontaneous law system, according to the aims and demands of the oppositive social sectors in a divided society like the Brazilian one.
\end{abstract}

De todos os temas fundamentais relativos à reforma constitucional ora em andamento, o do Judiciário é um dos que têm sido tratados de modo impreciso e incompleto. $O$ que é uma pena, pois a Constituinte poderia ser um excelente foro para o debate de questões como as do acesso diferenciado à justiça por parte dos diversos segmentos sociais, da reforma dos processos civil e penal, da criação de jurisdições especializadas para a agilização das soluções de feitos nas áreas de maior conflito e do papel dos tribunais enquanto instituição política e organização profissional para a produção de serviços jurídi-

(1) Professor-adjunto do Departamento de Filosofia e Teoria Geral do Direito da USP. Coordenador do GT sobre Direito e Sociedade da Associação Nacional de Pos-Graduação de Pesquisas e Ciências Sociais-Anpocs. 
cos - questões essas cuja relevância decorre das tensas relações entre a igualdade formal postulada pelos códigos e a desigualdade sócioeconômica bem como entre a justiça processual e a justiça social no âmbito de uma sociedade inequalitária, discriminatória e fracamente integrada. Nada disso, contudo, foi até agora discutido com um mínimo de profundidade pelos constituintes.

A maior parte das polêmicas se tem concentrado, quando muito, em torno de dois tópicos. O primeiro deles diz respeito à permanente reivindicação corporativa em favor de recursos financeiros capazes de modernizar a estrutura burocrática e acelerar a informatização dos tribunais. Reduzindo o problema do Judiciário a uma dimensão meramente técnica, fundada no tradicional princípio da neutralidade e da imparcialidade da função judicial, os velhos porta-vozes da magistratura limitam-se a atribuir as causas do crescente descompasso entre a realidade e os tribunais ao desaparelhamento e à sobrecarga de trabalho destes. $O$ segundo tópico diz respeito à transformação do Supremo Tribunal Federal numa Corte Constitucional. Apesar de passar da dimensão exclusivamente técnica para uma dimensão política na avaliação do papel do Judiciário, esta discussão acabou ficando restrita à forma pela qual aquela corte seria formada.

Por isso, nada garante que a nova Constituição venha a consagrar um Judiciário capaz de atuar com maior efetividade na justiça do caso concreto, substituindo a tutela dos indivíduos abstratamente considerados pelas normas gerais e impessoais pela tutela dos valores sociais inerentes a homens concretamente situados.

Afinal, diante de uma sociedade cada vez mais complexa, estarão os tribunais e seus magistrados aptos, funcional e tecnicamente, a lidar com conflitos classistas e transgressões de massa envolvendo grupos, classes e coletividades?

Dada a explosão de litigiosidade dos últimos tempos, da qual se destaca a crescente apropriação política e discursiva dos direitos humanos pelas entidades e associações populares, empenhadas em convertê-los em sinônimo de direito das maiorias marginalizadas, terão as diferentes instâncias judiciais condições de desempenhar com eficácia suas funções básicas de absorver tensões e reduzir as incertezas dos sistemas político e econômico, limitando os conflitos e impedindo sua generalização? 


\section{Em suma:}

- se as instituições de direito vigentes revelam-se incapazes de fornecer um sentido de ordem;

- se a consecução de uma ordem alternativa estável e legítima requer uma representação da vontade coletiva por meio da qual os grupos e classes em confronto se reconheçam como constitutivos de novo contrato político;

- se a Constituinte até hoje não foi capaz de ser a representação de uma vontade política legítima,

de que maneira o Judiciário poderá atuar tanto na reorganização do campo social em bases mais igualitárias quanto na consolidação de um sistema jurídico eficiente e reconhecido por todos como legítimo?

O tradicional isolamento do Judiciário da arena política jamais foi, entre nós, fruto do acaso. Pelo contrário, trata-se de uma premissa básica do modelo liberal-individualista de organização e conhecimento jurídico aqui desenvolvido desde o início da República - modelo esse do qual emergiu um sentimento difuso de que os juízes são funcionários do Estado, mas não são membros de seu poder político. A existência de tribunais superiores, capazes de reformar decisões e agir disciplinarmente sobre os juízes de primeira instância, também deu oportunidade a pensar-se que só eles, tribunais superiores, são efetivamente órgãos não-políticos do poder do Estado.

Dogmático e lógico-formal, tendo como contraponto a crença no equilíbrio entre os poderes e na separação entre o direito público e o direito privado, o modelo liberal-individualista da organização e conhecimento jurídico privilegia a lei como sinônimo de ordem, consagrando o princípio do pacta sunt servanda e aceitando o Estado como a principal fonte de direito. Graças a esse modelo, a cultura jurídica nacional se assenta sobre uma concepção orgânica de sociedade, segundo a qual os fenômenos econômicos e políticos devem ser analisados com vista a sua integração no funcionamento do sistema social globalmente considerado. A essa concepção subjaz, igualmente, o desejo de captação e enquadramento dos antagonismos cujo desenvolvimento escapa às malhas dos padrões normativos em vigor. Fora da lei, eis a palavra-de-ordem dessa cultura, o mundo está condenado à anarquia.

É por isso que a cultura jurídica nacional tende a fundir legitimidade com legalidade, substituindo a questão da justiça pela da va!i- 
dade formal das leis e concebendo o jurista, especialmente aquele encarregado de aplicar normas gerais a casos concretos, como o guardião de um sistema jurídico tido como completo e sem contradições. Ao enfatizar a subsunção dos fatos à prescrição legal, valorizando problemas como os da eliminação das antinomias e integração das lacunas, essa cultura assume um caráter inequivocamente idealista-positivista. Ou seja:

ela reduz o direito a um simples conjunto de normas, o qual se limita a dar sentido jurídico aos fatos sociais mediante o estabelecimento de uma relação de imputação entre atos ilícitos e sanções - relação essa que dá origem a uma sucessão de deveres jurídicos, o elemento primário dos códigos e da própria Constituição.

Tais deveres, em função da natureza instrumental e profissionalizante dessa cultura jurídica, não são por ela examinados em seus aspectos morais. Como as idéias morais estão acima da experiência e seu conteúdo varia ao infinito, ao jurista positivista interessa apenas a instituição das sanções para os casos de descumprimento das normas. O fato ilícito não é, em si, necessariamente imoral ou eticamente condenável; é, apenas, uma conduta contrária àquela fixada pela norma. O que importa é a determinação de um conjunto unitário de conceitos relacionados num discurso único e formalmente coerente, de modo que a organização científica do saber jurídico extrai seus critérios de ordem a partir da própria racionalidade do sistema normativo.

Expressas em normas abstratas e impessoais, as relações jurídicas estabelecidas pelo sistema legal definem tanto os parâmetros de coercibilidade quanto o controle racional dos cidadãos livres - indivíduos autônomos e integrantes da comunidade política. Como a responsabilidade pela edição dessas normas cabe ao Legislativo, já que a pedra angular do processo de legitimação do modelo liberal-individualista de organização jurídica é o princípio do equilíbrio entre os poderes, resta ao Executivo e ao Judiciário o dever de executá-las e aplicá-las de modo objetivo. Face à segurança propiciada pelo governo das leis, em cujo âmbito o juiz atua como conservador e transmissor das regras do sistema legal, a administração racional e os tribunais independentes se desenvolvem num quadro da mais absoluta previsibilidade.

No entanto, apesar de apregoada pelas corporações de advogados, consagrada pelos tribunais e canonizada pelas escolas 
de direito, qual o futuro dessa cultura legalista numa sociedade não-legalista, progressivamente marcada pelas confrontações de caráter coletivo?

Embora enraizada nos círculos jurídicos, terá essa cultura alguma correspondência com a tensa realidade de um país estigmatizado pelas contradições sociais e desigualdades econômicas?

Como é possível continuar postulando o princípio da igualdade formal perante a lei numa sociedade em que os $20 \%$ mais pobres detêm apenas $2 \%$ da riqueza nacional, enquanto os $20 \%$ mais ricos ficam com $66 \%$ ?

De que modo, no âmbito de uma formação social em que a pobreza atinge cerca de 64 a $69 \%$ da população, interpretar o princípio segundo o qual os juizes devem atender aos fins sociais e as exigências do bem comum na aplicação da lei?

Só a partir dessas indagações é que se pode entender o alcance do problema da reformulação do papel do Judiciário num contexto de transformação social, democratização política e reorganização constitucional, privilegiando-se as questões relativas à transformação do juiz num legislador ativo e criativo, consciente de que a justiça não pode ser reduzida a uma dimensão exclusivamente técnico-formal e de que o intérprete não consegue despojar-se de seus valores ideológicos na aplicação da lei ao caso concreto. Afinal, tais questões são suscitadas no momento em que a emergência de movimentos comunitários, sindicais e religiosos desafia a rigidez lógico-formal dos sistemas legais/judiciais, mediante a politização de temas aparentemente técnicos e a tentativa de criação de novos direitos a partir de fatos consumados. Foi por isso que, em maio, procurando influir na Constituinte, a Associação Paulista de Magistrados patrocinou um debate sobre temas cuja simples enunciação implica uma recusa dos princípios básicos da nossa cultura jurídica. Tais juízes revelaram sensibilidade ao perceber que, desde o advento dos Estados burocrático-autoritários e dos processos de industrialização/pauperização da América Latina, quanto mais cresceram as reivindicações populares mais limitada tornou-se a atuação do Judiciário, quer pelas leis às quais se via ligado, quer pela cultura na qual se formam os atores jurídicos, quer por estarem os tribunais lançados no meio de crises políticas envolvendo grupos de reivindicação e outros poderes do Estado. Diante de 
tais pressões, muitas vezes o Judiciário se viu, nos anos cinzentos da segurança nacional, inclinado mais a admitir restrições impostas pelo Executivo à sua autonomia do que a deixar-se questionar pelas massas empobrecidas.

Evidentemente, há um preço a se pagar por essa recusa: a descoberta de que a neutralidade e a imparcialidade do Judiciário não passam de uma ficção cultivada por uma cultura jurídica isolada e idealista. É natural que guardiães dessa cultura, com sua visão de mundo legalista-profissionalizante e com seu saber pretensamente racional e supostamente não-ideológico, tenham recebido com reservas a iniciativa dos magistrados paulistas. $O$ que não podem negar, porém, é a lógica dos argumentos invocados pelas associações de magistrados comprometidos, no debate constitucional, mais com a qualidade do padrão de resposta social e política que o Judiciário pode oferecer à sociedade do que com a mera defesa corporativa e estamental de vantagens funcionais.

O ponto de partida desses argumentos é claro: se a sociedade encontra-se fragmentada em classes, se a própria Constituinte está dividida entre partidos e se o governo é composto de ministros representando diversos partidos, não se pode ignorar o caráter político-ideológico da atual e da futura ordem constitucional. É impossível negar que os textos legais, mesmo quando aprovados no Legislativo por um único partido com bancada majoritária, valem para todos. Por isso, se os decretos impostos por um ministro do PMDB valem erga omnes tanto quanto os decretos impostos por ministros do PFL, haveria algo de mais em saber que um tribunal é composto por juízes que pensam politicamente deste ou daquele modo? A verdade é que os cidadãos estariam melhor informados das razões de decidir de cada magistrado caso suas inclinações ideológicas fossem conhecidas, não encobertas pelo véu da neutralidade. Afinal, do mesmo modo como os tribunais compõem o aparelho de Estado, os juízes também exercem, com ou sem consciência, uma função política.

Os guardiães da cultura dogmática, lógico-formal e idealista poderão dizer que uma dada visão de mundo não é, obrigatoriamente, uma visão político-partidária. Estarão certos? Provavelmente não, pois o que são as jurisprudências dominantes senão programas políticos vitoriosos no âmbito dos tribunais? $\mathrm{E}$ a escolha dos juízes, não estando ligada à votação do conjunto de cidadãos, por acaso estaria desligada de critérios políticos por parte dos tribunais superiores? E 


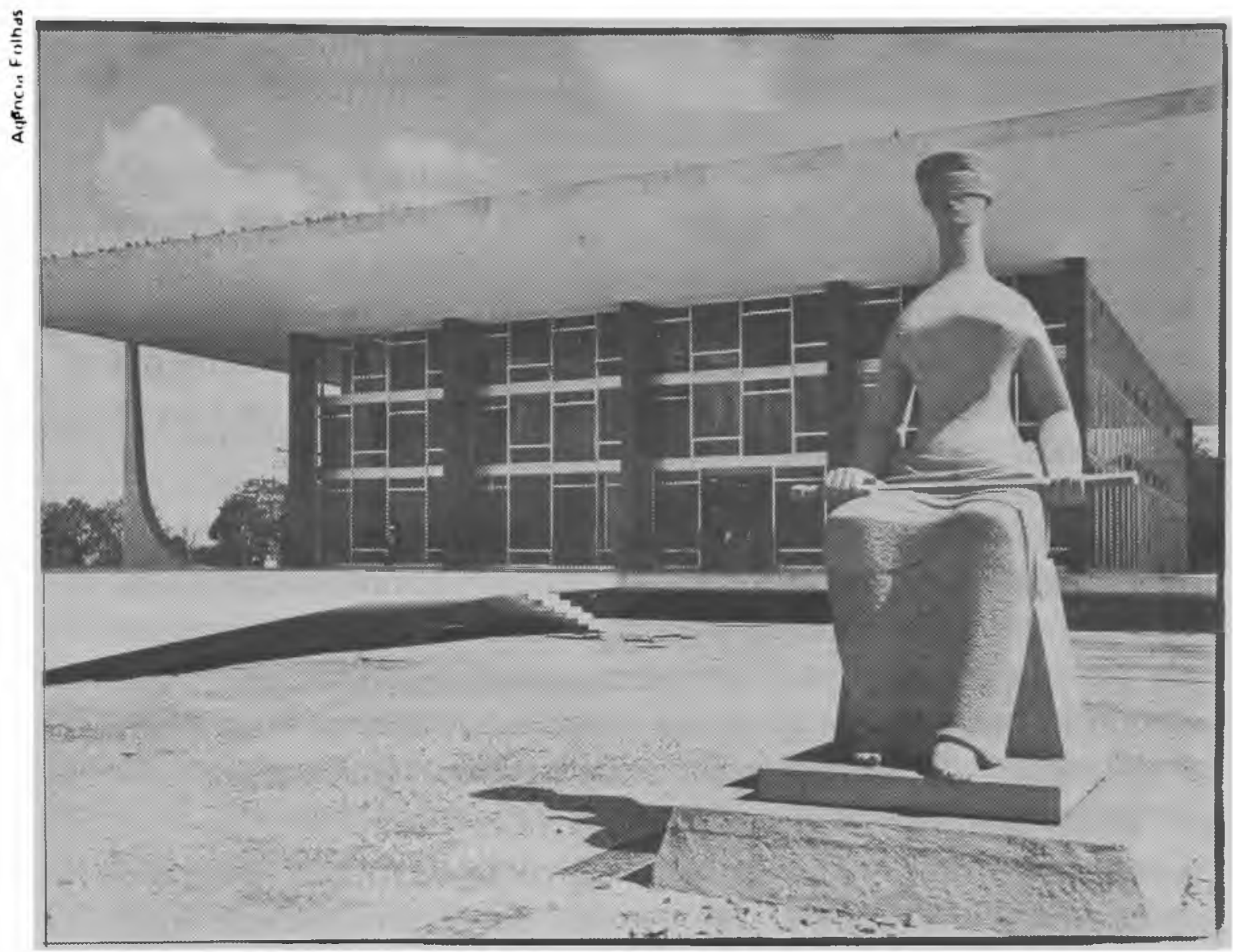

Vista do Supremo Tribunal Federal, em Brasília.

certo que se poderia fazer uma distinção entre os partidos que atuam no governo ou no parlamento e as associações judiciais. Todavia, nada impede que, dentro da magistratura, sejam explicitadas as tendências políticas e jurídicas ali instaladas.

Na verdade, a idéia de que a magistratura decide acima das situações históricas e de que ela só está sujeita à lei inclui um preço a pagar pois a afasta da efervescência cultural do resto da sociedade. Ao mesmo tempo, também a impede de entender as razões pelas quais os códigos de direito privado, apesar dos projetos já apresentados para sua modernização, encontram-se superados pela velocidade das transformações sócio-econômicas. Hoje a cultura jurídica não é mais produzida apenas nas academias, porém, igualmente, fora dela. Trata-se de uma cultura que ultrapassa os limites fixados pela dogmática tradicional e nem por isso é ilógica ou irracional. A cultura dos códigos não é a única usada pelos magistrados, mas é mitificada como sendo a que oferece resposta para tudo. A circulação de uma vulgata kelseniana tem ocultado o rigor do próprio Kelsen, que reconhecia na decisão judicial um ato não-submetido à lógica do sistema pensado pelos juristas. Além disso, embora a crônica falta de verbas do Judiciário seja 
um problema real, a grande questão continua ignorada no debate constitucional:

"o estar a magistratura formada numa cultura jurídica incapaz de entender a sociedade e seus conflitos e a má vontade em discutir-se tanto a democratização efetiva deste braço do Estado quanto a tendência de muitos setores sociais em buscar fórmulas inéditas para auto-regular seus próprios conflitos, mediante mecanismos mais informais de arbitragem e negociação de suas divergências"

Como tornar o Judiciário sensível aos anseios de uma sociedade que deseja expor seus conflitos, conquistando novos espaços para a racionalidade material (a justiça substantiva) em detrimento da racionalidade formal (a justiça neutra e imparcial), como condição de um processo de legitimação política mais complexo e impossível de ser ordenado pelas normas rígidas e fechadas forjadas pelo liberalismo jurídico?

Como possibilitar a efetiva democratização da função jurisdicional e permitir a abertura de novos canais de comunicação institucional com a sociedade e com a cultura do Brasil contemporâneo?

Como ampliar a capacidade adaptativa e aprendizagem de instituições de direito baseadas em princípios organizacionais ortodoxos, os quais vêm sendo erodidos pela emergência de um direito achado na rua, pouco sistematizado e brotado casuisticamente de relações sociais contraditórias?

Decorre daí o equivoco da Constituinte, caso venha a manter a atual estrutura do Judiciário.

O que os constituintes precisam ver é que os tribunais, caso Ihes fosse dada liberdade interpretativa a partir de modelos e categorias jurídicas plásticas e abrangentes, poderiam abrir caminho para a elaboração de um direito mais justo e eficaz no interior dessas relações sociais, na medida em que os juízes teriam condições de adequar procedimentos formais originais à formulação de uma nova vontade coletiva.

Dito de outro modo:

como no espaço judicial pode emergir um direito original e legítimo, voltado mais à questão da justiça substantiva do que com meros problemas de ritos, prazos e técnicas legais, uma magistra- 
tura com poderes decisórios ampliados e com um conhecimento multidisciplinar teria condições de reformular os conceitos fechados e tipificantes dos sistemas legais vigentes a partir das próprias contradições sociais. Sob pena de o Judiciário, se mantida sua estrutura atual, ver progressivamente esgotada tanto a operacionalidade quanto o acatamento de suas decisões face à expansão de conflitos coletivos.

Um bom exemplo desse esgotamento vem ocorrendo no caso das ocupações de terras: os ocupadores, hoje, tendem a desconfirmar a autoridade do Judiciário quando seus magistrados, comportando-se como técnicos preocupados em fazer das sentenças meras operações lógicas, insistem em equacionar os conflitos estritamente com base na concepção de direito de propriedade estabelecida no Código Civil. Curiosamente, tal desconfirmação só não tem sido verificada nos processos judiciais em que os juízes substituíram essa concepção por uma outra, segundo a qual o direito à moradia social é concebido como uma efetiva limitação ao direito de usar e dispor por parte dos proprietários ${ }^{1} 1$ ). Esse exemplo mostra que os atores envolvidos nesse tipo de conflito usam instrumentalmente quer o sistema legal vigente quer a possibilidade de sua reformulação por vias judiciais. Na medida em que proprietários e ocupadores defendem concepções distintas e excludentes do direito de propriedade, o intérprete se vê assim preso a um difícil dilema: o de tentar manter o espírito do sistema legal vigente, atualizando certas normas dentro de um limite razoável de flexibilidade e adaptando-as jurisprudencialmente como verdadeiras regras conectivas, atribuindo-Ihes função de especificar e conciliar a generalidade das prescrições em vigor com a nova realidade; ou de tentar resolver o problema em si, deixando de lado algumas das limitações formais a que os magistrados estão submetidos, bem como o próprio ethos profissional da corporação, para agir como uma espécie de arquiteto social.

No primeiro caso, ao empenhar-se em mudar topicamente o sentido de certas prescrições para reforçar o sentimento geral da legalidade, para que as partes assumam diretamente sua quota de responsabi-

(1) Veja-se, como ilustração, a seguinte decisão: "Levando a realidade de São Paulo à presunção de que os favelados são pessoas comuns, pois as favelas cada vez mais se estabilizam nesta cidade, e que aqueles não são necessariamente vadios ou marginais, mas apenas pobres, não há como se afastar a aplicação do princípio constitucional da função social da propriedade, mesmo porque não há, nos autos, prova alguma de que os possuidores sejam marginais do ponto de vista juridico-penal". Cf. 10 Tribunal de Alçada Civil, $3^{3}$ Câmara, Acórdão n. 291.722/SP, em 02/12/81. 
lidade na defesa do direito positivo, os juízes correm o risco de ver suas decisões praeter legem desafiadas por uma situação de fato - o que tornaria suas sentenças ineficazes. No segundo caso, ao esforçarse pela revitalização do Judiciário como agente ativo na construção de uma ordem legal mais descentralizada, dado o efeito legitimador de retorno que o alargamento das funções judiciais passa a ter sobre todo o sistema social, os juízes correm outro tipo de risco: o de, em nome do princípio de certeza jurídica, terem suas sentenças conta-legem reforçadas pelos diferentes procedimentos de controle funcional e ideológico criados pelo próprio Judiciário (sob a forma de correições e recursos ex-officio, para policiar a si mesmo - entre outras razões, para evitar que alguns magistrados deflagrem isoladamente processos autonomizantes de legitimação por meio de sua atividade decisório-criadora em cada caso concreto.

O que o exemplo acima revela, pois, são o sentido e o alcance da crise vivida pelo Judiciário, em cujo âmbito se desenvolvem interações conflitantes e convivências contraditórias entre uma concepção de ordem legal e uma concepção alternativa de ordem justa. Como afirmam os integrantes de um importante movimento político na área do direito, o Gabinete de Assessoria Jurídica às Organizações Populares, chamando atenção para esse problema, "a utilização das nor. mas vigentes não significa adesão à ordem legal injusta. $O$ direito deve ser criticado sempre que não corresponda aos desejos populares. Ocorre que as normas podem ser um eficiente instrumento de defesa do povo. O desprezo pela via jurídica como solução para certos problemas implica no desperdício de uma oportunidade para a conquista de ganhos reais. Existem determinadas leis que favorecem, sob diversos aspectos, as lutas populares e resultam não apenas da vontade das classes dominantes, mas do somatório de vários fatores que concorrem para a produção do Direito. O desprezo à legalidade reflete uma tentativa de se alienar, fugindo de uma realidade difícil e, muitas vezes, cruel. Ao assessor jurídico compete desmitificar o direito, decodificar a linguagem jurídica, hermética e ininteligível para o leigo, esclarecendo o fato à \uz das normas e alertando, inclusive, para os desdobramentos de ordem politica que podem ter as diversas opções de decisão." 11$)$

(1) Cadernos GAJOP. Olinda, 1985, n: 2, p. $49-50$ 


\section{CONCLUSÃO}

Nesta hora em que a transição democrática se torna um desejo irrecusável e um desafio irreversível, e em que a reordenação institucional do País depende menos de uma estrutura constitucional programada ex ante e mais de um intrincado processo em cujo âmbito se desenvolvem múltiplas estratégias de negociação visando como resultado ex post uma nova ordem jurídico-política, é impossível deixar de correr riscos. É por esse motivo que, subjacente à crise de identidade do Jụdiciário, também não se pode desconsiderar o questionamento dos princípios ideológicos da cultura jurídica nacional, especialmente aqueles segundo os quais o direito seria neutro; a norma, ponto de equilíbrio entre interesses conflitantes; e os juízes, meros executores de operações lógico-formais. A grande dificuldade com que essa cultura se defronta é sua incapacidade de explicitar o poder social das significações jurídicas, a fim de esclarecer como os pontos de vista imanentes e formais (que comandam a produção da Ciência do Direito entre nós) expressam funções sociais específicas, enquanto elementos constitutivos dos efeitos materiais da lei na sociedade. Acima de tudo, pois, é necessário que essa cultura seja reformulada integralmente, deixando-se sensibilizar pelos segmentos sociais que, historicamente, nunca foram efetivamente beneficiados pelas instituições do direito nem tiveram acesso aos tribunais.

\section{AGRADECIMENTOS}

Agradeço os comentários, críticas e sugestões feitas por José Reinaldo Lima Lopes, do Departamento de Filosofia e Teoria Geral do Direito da USP que foram incorporados tanto quanto possível no corpo deste artigo. A responsabilidade do autor, evidentemente, não diminui com o auxílio recebido.

\section{FICHA CATALOGRÁFICA}

FARIA, J.E. A Constituinte, a justiça e a magistratura. Revista da Universidade de São Paulo. São Paulo, (6): 9-19, jul./set. 1987 